\title{
Mini Sternotomy and Mini Thoracotomy for Aortic Valve Replacement: Is There a Difference?
}

\author{
Faisal Mourad, MD, Mohammed Abd Al Jawad, MD \\ Department of Cardiothoracic Surgery, Ain Shams University, Cairo, Egypt
}

\section{ABSTRACT}

Background: Minimally invasive valve replacement is increasingly accepted among surgeons and patients alike. Ministernotomy and minithoracotomy are the most used incisions in the minimally aortic valve replacement. The superiority of one incision over the other still is debatable with a few centers having the opportunity to compare them head-to-head.

Methods: A retrospective analysis of 260 patients, who underwent mini AVR, with 132 patients in the ministernotomy group and 128 patients in the minithoracotomy group. Operative details, mortality, wound cosmetics, and postoperative pain were among the primary end points.

Results: A predominance of female gender has been observed in both groups. The cross-clamp and total bypass times were significantly lower in MS compared with the MT approach $(63.61 \pm 16.115$ vs. $70.75 \pm 33.274 \mathrm{~min}, P=0.028$, and $91.90 \pm 26.365$ vs. $112.24 \pm 51.634 \mathrm{~min}, P<0.001$, respectively). The minithoracotomy group had significantly shorter lengths of wounds $(5.1 \pm 0.6$ vs. $8.48 \pm 0.344 \mathrm{~cm}, P<0.001)$. The ministernotomy group had significantly lower postoperative pain scores either in the ICU, at hospital discharge, or after 30 days at the outpatient clinic, where scores compared with MT $(4.46 \pm 1.23$ vs. $5.23 \pm 1.12, P<0.001,1.6 \pm 0.84$ vs. $1.83 \pm 0.72, P$ $=0.019$, and $1.28 \pm 0.67$ vs. $1.47 \pm 0.53, P=0.012$, respectively).

Conclusion: Both minimally invasive incisions for AVR proved their safety and efficacy. While the ministernotomy has the advantage of less postoperative pain and pleural complications, the minithoracotomy incision has its unmatched aesthetic appeal.

\section{INTRODUCTION}

In developed countries, aortic diseases are the most common valvular heart conditions, and their effects on public health and healthcare services are expected to grow as the population ages [Bonow 2015]. Aortic valve replacement via

Received fune 6, 2021; accepted fune 28, 2021.

Correspondence: Dr. Faisal Mourad, MD, Associate Professor of Cardiothoracic Surgery, Department of Cardiothoracic Surgery, Ain Shams University, Abbaseya Square, Cairo, Egypt, Telephone +201063436666 (e-mail: faisalmourad@botmail.com). median sternotomy has been considered the "gold standard" to which all other interventions are compared [Brown 2009].

Anesthesia, surgical procedures, postoperative care, and myocardial protection strategies all have evolved, allowing surgeons to safely treat patients of advanced age and comorbidity with a low risk of morbidity and mortality. As a result, a newer contemporary trend toward minimal invasive surgery has been introduced into cardiac surgery, which aims to provide better outcomes for patients while maintaining the same level of quality as traditional median sternotomy [Bonacchi 2002].

Aortic valve surgery has advanced significantly in recent years because of the increased acceptance of less invasive procedures and emerging technologies. Indeed, a growing number of surgeons are treating aortic valve diseases with smaller chest incisions to reduce the surgical procedure's "invasiveness" while also improving clinical and cosmetic outcomes [Nguyen 2017].

The upper ministernotomy (MS) and right anterior minithoracotomy (MT) are the most used approaches for minimally invasive aortic valve replacement now. Even though both methods produce excellent clinical results, MS is the more preferred method. When compared with MS, minithoracotomy is a more technically challenging operative approach that necessitates advanced procedures, appropriate surgical equipment, precise patient selection, and a welldefined preoperative preparation. In contrast, both from a surgical and anesthesiologist standpoint, AVR using an MS approach is very close to traditional AVR. Furthermore, when compared with minithoracotomy, MS requires a minimal learning curve and is associated with shorter operative times [Olds 2019; Ghanta 2015].

The aim of this study is to compare the safety and efficacy of AVR via the two commonly used minimally invasive approaches: ministernotomy to minithoracotomy.

\section{PATIENTS AND METHODS}

A retrospective comparative observational study was conducted among patients who underwent isolated, elective, primary minimally invasive aortic valve replacement from May 2014 through December 2020. Those with preoperative renal impairment (i.e., serum creatinine $>1.5 \mathrm{mg} / \mathrm{dl}$, blood urea $>100 \mathrm{mg} / \mathrm{dl}$, and $\mathrm{K}+>5 \mathrm{meq} / \mathrm{L})$, patients with rhythm defects by electrocardiography, and those with preoperative $\mathrm{O} 2$ saturation $<90 \%$ by pulse oximetry were excluded from final analysis. This study was approved by the Research 
Ethics Committee (REC) at the Faculty of Medicine, Ain Shams University under the number code (FWA 000017585, FAMSU R 88 /2021).

A total of 273 patients initially were recruited from the registry of the operated patients. After applying selection criteria, 260 patients were enrolled in this retrospective analysis. Medical records were reviewed for prospectively collected data, including demographics, operative steps, ICU course, inotropic support, permanent pacemaker insertion, wound infection, length of wound, and hospital stay. Numerical pain score $(0-10)$ was used for the patients to subjectively rate their pain, where 0 means "no pain," 1-3 for mild, 4-7 is moderate, and above 8 to be severe pain.

Operative details - ministernotomy: Skin incision started $1 \mathrm{~cm}$ above the angle of Luis down to the level of the 4th intercostal space (ICS). The sternal saw was engaged in the upper manubrium, going caudally at the level of the right 4th ICS (J Sternotomy). The pericardium was opened after dissecting the thymus gland and identifying the left innominate vein. The ascending aorta and right atrium were cannulated centrally. Venting was done either through the pulmonary artery or right superior pulmonary vein. An aortic root cannula was inserted for cardioplegia administration and de-airing.

Myocardial protection was achieved with systemic hypothermia $\left(28-32^{\circ} \mathrm{C}\right)$, and antegrade cold blood/tepid cardioplegia $(15-20 \mathrm{ml} / \mathrm{Kg}$ as an initial dose followed by $2-10 \mathrm{ml} / \mathrm{kg}$ every 20-30 minutes).
Operative details - minithoracotomy: MT was performed through the second or third right intercostal space (planned by preoperative CT). In all cases, surgical peripheral cannulation (femoral artery and vein) was performed. The ascending aorta was clamped directly through the MT, and anterograde warm blood cardioplegia (repeated every 20-30 minutes) was given in the aortic root or, selectively, into the coronary ostia.

The valve implantation technique was the same in MT and MS. Intraoperative transoesophageal echocardiography was applied in all cases and used for the assessment of cardiac function, air removal, and correct positioning and function of the aortic valvular prosthesis.

Statistical analysis: The collected data were revised, coded tabulated, and introduced to the PC using Statistical Package for Social Science SPSS (SPSS Inc, Chicago, IL, USA). Data were presented as mean $\pm S D$ and numbers (percentages), as indicated. Quantitative data were analyzed using Student's test or analysis of variance, as indicated. The distribution of qualitative variance was analyzed by compared Chi square test (Fisher's extract test), as indicated.

\section{RESULTS}

Of a total number of 260 patients, 132 patients had their valve replaced via MS, while the remaining 128 patients underwent MT. Most of our cohort, 168 patients, were of

Table 1. Patient demographics and characteristics

\begin{tabular}{|c|c|c|c|c|}
\hline Age (mean $\pm S D)$ & $61.04 \pm 6.48$ & $59.81 \pm 7.33$ & 1.435 & 0.153 \\
\hline Female & $94(71.2 \%)$ & $74(57.8 \%)$ & 5.103 & $0.024 *$ \\
\hline Male & $38(28.8 \%)$ & $54(42.2 \%)$ & & \\
\hline Diabetes mellitus & $57(43.2 \%)$ & $56(43.8 \%)$ & 0.009 & 0.926 \\
\hline Hypertension & 70 (53.0\%) & $73(57.0 \%)$ & 0.420 & 0.517 \\
\hline NYHA class I-II & $46(34.8 \%)$ & $64(50 \%)$ & 6.112 & $0.013 *$ \\
\hline NYHA class III-IV & $86(65.2 \%)$ & $64(50 \%)$ & & \\
\hline Preoperative LVEF & $60.36 \pm 7.66$ & $61.08 \pm 6.37$ & 0.823 & 0.411 \\
\hline \multicolumn{5}{|l|}{ Valve affection } \\
\hline Aortic stenosis & $53(40.2 \%)$ & $63(49.2 \%)$ & 2.162 & 0.141 \\
\hline Aortic regurgitation & 57 (43.2\%) & $41(32.0 \%)$ & 3.440 & 0.064 \\
\hline Combined & $22(16.7 \%)$ & $24(18.8 \%)$ & 0.194 & 0.660 \\
\hline
\end{tabular}

Values are shown in mean \pm SD and percentage; SD, standard deviation; BMI, body mass index; NYHA, New York Heart Association; LVEF, left ventricular ejection fraction; PAP, pulmonary artery pressure 
female gender, with a statistically significant predominance of MS among females $(P=0.024)$. (Table 1$)$

Though the age groups and preoperative LV functions were comparable among both groups without any significant statistical difference, the MS was the dominant preferred intervention among patients with preoperative NYHA class III-IV (Table 1).

A closer look into the operative details shows many interesting differences between both approaches. The MS approach required more time to achieve full cardiopulmonary support $(44.14 \pm 2.786 \mathrm{~min})$ whereas, the MT approach required significantly lower times in comparison $(23.66 \pm 6.062 \mathrm{~min}, P<$ 0.001). (Table 2)

On the other hand, the cross-clamp and total bypass times were significantly lower in MS compared with the MT approach $(63.61 \pm 16.115$ vs. $70.75 \pm 33.274 \mathrm{~min}, P=0.028$, and $91.90 \pm 26.365$ vs. $112.24 \pm 51.634 \mathrm{~min}, P<0.001$, respectively (Table 2).

As for patient satisfaction, in terms of the length of incision and postoperative pain, the MT group had significantly shorter lengths of wounds $(5.1 \pm 0.6$ vs. $8.48 \pm 0.344 \mathrm{~cm}, P<$ 0.001 (Table 2). However, this is quite the opposite when it comes to postoperative pain score either in the ICU, at hospital discharge, or after 30 days at the outpatient clinic, where the MS had significantly lower scores compared with MT ( $4.46 \pm 1.23$ vs. $5.23 \pm 1.12, P<0.001,1.6 \pm 0.84$ vs. $1.83 \pm 0.72, P$ $=0.019$, and $1.28 \pm 0.67$ vs. $1.47 \pm 0.53, P=0.012$, respectively. (Table 3)

The rate of conversion was higher than usual in the current study since it included patients representing the very early stages of learning curve for our surgeons, where all re-explorations were converted to full sternotomy for better exposure and avoidance of unnecessary mortality (Tables 2, 3).

The reaccumulating pericardial/pleural effusion is mainly attributed to the nature of our patient cohort, where they prefer mechanical over bioprosthesis, and our institutional protocol of keeping INR levels near 3. We believe that all these factors have led to the increased rates of pericardial/ pleural effusion (Table 3).

Postoperative transvalvular mean pressure gradient of implanted valves was significantly higher in the MT group $(20.24 \pm 4.89 \mathrm{mmHg})$ compared with the MS group $(17.15 \pm 5.35 \mathrm{mmHg}, P<0.001$ (Table 3$)$.

\section{DISCUSSION}

Since its very own beginning, cardiac surgery via median sternotomy has been the gold standard for aortic valve replacement, in terms of patient safety, good surgical exposure, and reproducibility [Falk 2017]. However, one of the major setbacks of this incision is its lengthy healing duration relative to the mini-incisions along with its cosmetic impact and psychological acceptance of scar [Massimo 1999]. The appreciation of body image satisfaction has become a major concern for many patients, especially female patients [Durdu 2018]. Our cohort was no different since the majority (168 patients) were of female gender.
In depth analysis of our cohort showed the ministernotomy to be the preferred technique. This is due to the easier technicality, lesser learning curve, and similarity to the standard sternotomy. Also, the ministernotomy group had a significantly higher number of patients with NYHA class III-IV, denoting more surgeons' preference toward their comfort zone. This is consistent with major literature preferring the ministernotomy over minithoracotomy [Bonacchi 2021].

Scar size and postoperative pain are important factors affecting patients' perception and readiness for surgery [Massimo 1999]. The minithoracotmy incision is more aesthetic and considerably smaller compared with ministernotomy $(5.1 \pm 0.6 \mathrm{~cm}$ vs. $8.48 \pm 0.344 \mathrm{~cm}$, respectively $)$, even some patients used to conceal it with clothes or tattoo imprints, unlike ministernotomy scar. However, it has been associated with significant postoperative pain in the ICU, at hospital discharge, and even after 30 days (Table 3 ).

From the technical point of view, achieving peripheral cannulation required less time in minithoracotomy compared with the central cannulation in ministernotomy. Total bypass and cross-clamp times were significantly shorter in ministernotomy. Comparing these data individually to median sternotomy proves the efficacy of both incisions [Jahangiri 2019].

The early outcomes of both techniques, namely mortality, ICU and hospital stay, and rate of conversion to full sternotomy showed no superiority of one technique over the other. A debate still goes on in many studies [Bonacchi 2021; Schmitto 2010].

The respiratory related complications were higher in the minithoracotomy group, though they showed speedy recovery and weaning off ventilatory support. They showed an increase in pleural drainage, mostly due to loss of pleural integrity. The results are partially inconsistent with other reports of less ventilation times in ministernotomy [Bonacchi 2021].

The minimally invasive techniques have proved both safety and efficacy in AVR, with data suggesting superiority of one over the other still inconclusive. However, the main surgical challenge is the alternative valve implantation techniques via catheter (TAVI) especially with the PARTNER 3 trial results, suggesting a trend toward low-risk patients. Minimally invasive techniques, which take considerable operative time and come with a learning curve, can still fight back. The introduction of rapid deployment and sutureless valves can significantly cut the operative times and offer mini techniques to the high-risk aortic stenosis patients denied surgery before [Amer 2020; Tanaka 2021].

The study has the limitations of a small number of patients, being of a single center, and the inherit defects of a retrospective analysis. The lack of comparison to standard median sternotomy also adds to the limitation. Also, a patient satisfaction questionnaire could not be conducted in the current study.

\section{CONCLUSION}

Minimally invasive aortic valve replacement is a safe and efficient technique. The minithoracotomy is more technically 
Table2. Surgical details

\begin{tabular}{|c|c|c|c|c|}
\hline Time to cannulation ( $\mathrm{min}$ ) & $44.14 \pm 2.786$ & $23.66 \pm 6.062$ & 35.174 & $<0.001 *$ \\
\hline Total bypass time ( $\mathrm{min}$ ) & $91.90 \pm 26.365$ & $112.24 \pm 51.634$ & 4.018 & $<0.001 *$ \\
\hline Length of incision $(\mathrm{cm})$ & $8.48 \pm 0.344$ & $5.1 \pm 0.6$ & 55.934 & $<0.001 *$ \\
\hline Inotrope support & $78(59.1 \%)$ & $96(75.0 \%)$ & 7.430 & $0.006 *$ \\
\hline Conversion to full sternotomy & $8(6.1 \%)$ & $12(9.4 \%)$ & 1.005 & 0.316 \\
\hline $\begin{array}{l}\text { Paravalvular leak as evidenced by } \\
\text { intraoperative TEE (mod-severe) }\end{array}$ & $1(0.8 \%)$ & $1(0.8 \%)$ & 0.000 & 0.983 \\
\hline
\end{tabular}

Values are shown in mean \pm SD and percentage; SD, standard deviation; DC, cardioversion; TEE, transesophageal echocardiography

Table 3. Postoperative course

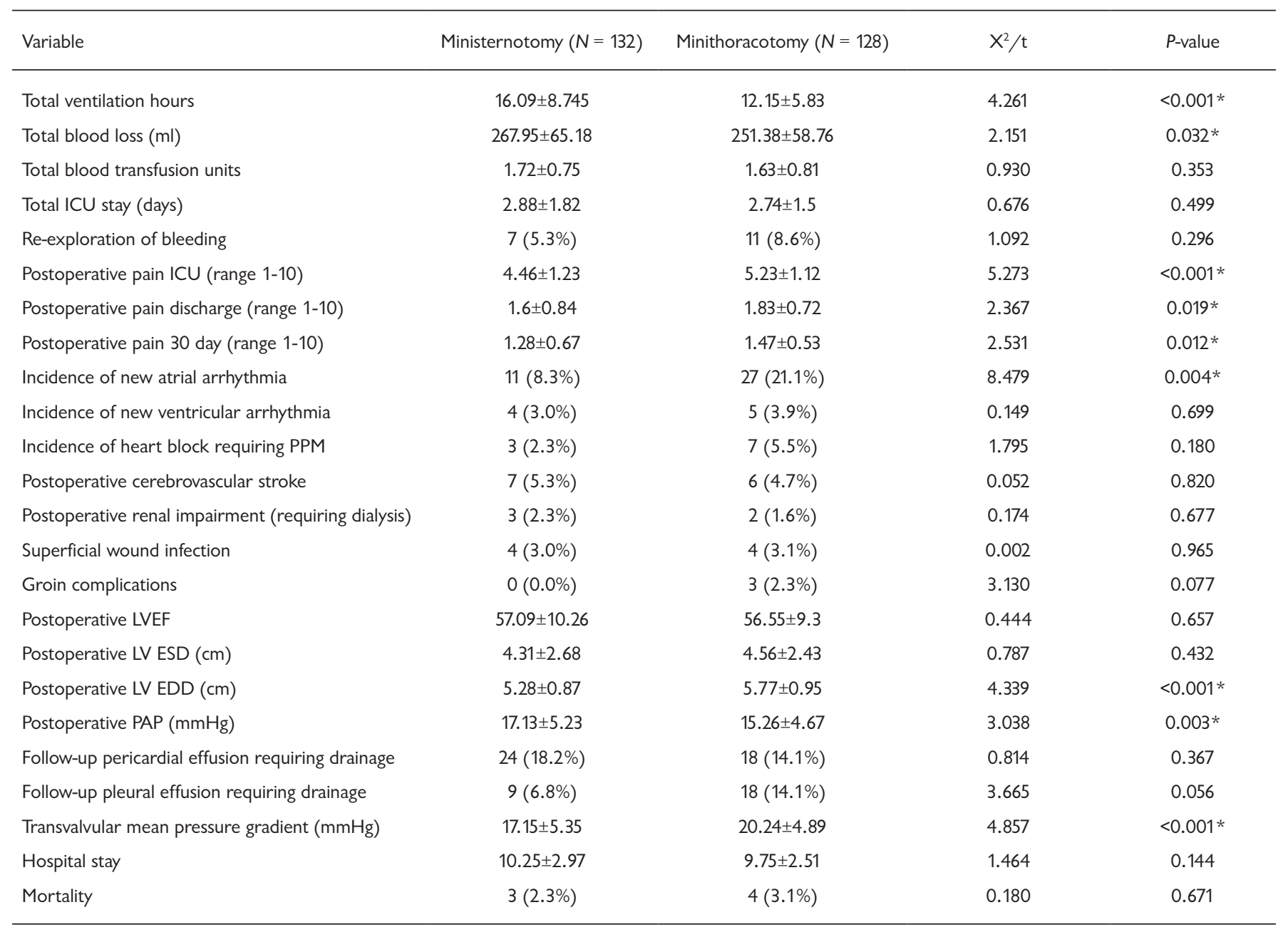

Values are shown in mean \pm SD and percentage; SD, standard deviation; PPM, permanent pacemaker 
challenging and is associated with more postoperative pain but is rewarded with better aesthetics. The ministernotomy requires a non-steep learning curve and easily can be adopted by newly trained surgeons to lure them from their comfort zone.

\section{REFERENCES}

Amer M, Al Jawad MA, Omar A, Metwaly H. 2020. Safety and Haemodynamic Outcomes of Currently Available Suture-less Aortic Valves in Patients With Aortic Stenosis: A Meta-Analysis. Heart, Lung and Circulation. 29(9):1301-1309.

Bonacchi M, Dokollari A, Parise O, et al. 2021. Ministernotomy compared with right anterior minithoracotomy for aortic valve surgery. The Journal of Thoracic and Cardiovascular Surgery.

Bonacchi M, Prifti E, Giunti G, Frati G, Sani G. 2002. Does ministernotomy improve postoperative outcome in aortic valve operation? A prospective randomized study. The Annals of Thoracic Surgery. 73(2):460-465.

Bonow RO, Greenland P. 2015. Population-Wide Trends in Aortic Stenosis Incidence and Outcomes. Circulation. 131(11):969-971.

Brown JM, O'Brien SM, Wu C, Sikora JA, Griffith BP, Gammie JS. 2009. Isolated aortic valve replacement in North America comprising 108,687 patients in 10 years: Changes in risks, valve types, and outcomes in the Society of Thoracic Surgeons National Database. The Journal of Thoracic and Cardiovascular Surgery. 137(1):82-90.

Durdu MS, Baran Ç, Gümü F, et al. 2018. Comparison of minimally invasive cardiac surgery incisions: Periareolar approach in female patients. Anatol J Cardiol. 20(5):283-288.

Falk V, Baumgartner H, Bax JJ, De Bonis M, Hamm C, Holm PJ, et al. 2017. ESC Scientific Document Group. 2017 ESC/EACTS Guidelines for the management of valvular heart disease. Eur J Cardiothorac Surg. 52:616-64.

Ghanta RK, Lapar DJ, Kern JA, et al. 2015. Minimally invasive aortic valve replacement provides equivalent outcomes at reduced cost compared with conventional aortic valve replacement: A real-world multiinstitutional analysis. The Journal of Thoracic and Cardiovascular Surgery. 149(4):1060-1065.

Jahangiri M, Hussain A, Akowuah E. 2019. Minimally invasive surgical aortic valve replacement. Heart. 105(Suppl 2):s10-5.

Massimo Massetti, Patrick Nataf, Gerard Babatasi, André Khayat. 1999. Cosmetic aspects in minimally invasive cardiac surgery, European Journal of Cardio-Thoracic Surgery, Volume 16, Issue Supplement_2, November. Pages S73-S75.

Nguyen TC, Terwelp MD, Thourani VH, et al. 2017. Clinical trends in surgical, minimally invasive and transcatheter aortic valve replacement $†$. European Journal of Cardio-Thoracic Surgery. 51(6):1086-1092.

Olds A, Saadat S, Azzolini A, et al. 2019. Improved operative and recovery times with mini-thoracotomy aortic valve replacement. Journal of Cardiothoracic Surgery. 14(1).

Schmitto JD, Mokashi SA, Cohn LH. 2010. Minimally-invasive valve surgery: the state of the art. J Am Coll Cardiol. 56:455-62.

Tanaka, D, Nedadur, R, Yanagawa, B. 2021. Rapid deployment valves: Another tool in the toolbox. J Card Surg. 1- 2. 